\title{
PENGEMBANGAN SISTEM INFORMASI MANAJEMEN ADMINISTRASI IZIN (SIMAMI) DI UNIVERSITAS TEKNOLOGI SUMBAWA
}

\author{
Sirajunnasihin $^{1 *}$, Tomy Dwi Cahyono ${ }^{2}$, Wilia Ismiyarti ${ }^{3}$ \\ 1,3 Informatika, Universitas Teknologi Sumbawa \\ ${ }^{2}$ Teknologi Hasil Pertanian, Universitas Teknologi Sumbawa \\ email: sirajunnasihin@uts.ac.id*
}

\begin{abstract}
Abstrak: Penelitian ini bertujuan untuk mengembangkan sistem informasi manajemen administrasi izin di universitas teknologi sumbawa agar dapat mempermudah aktifitas pengelolaan data dan pengajuan izin seluruh dosen maupun staf universitas teknologi sumbawa. Penelitian menggunakan metode deskriptif kualitatif untuk dapat menggambarkan keadaan ditempat penelitian dengan mendetail dan memungkinkan dapat berkembang selama proses penelitian berlangsung. Metode perancangan perangkat lunak ini menggunakan metode waterfall. Metode pengumpulan data menggunkan obervasi, studi pustaka dan studi dokumen. Hasil dari penelitian ini adalah sebuah sistem yang telah dikembangkan sehingga dapat membantu mempermudah pegawai dalam melakukan izin sehar-hari maupun cuti dan mempermudah bagian kepegawaian dalam melakukan pengelolaan data izin dan cuti
\end{abstract}

Kata Kunci : Web, Izin, Cuti, Sistem, Informasi

Abstract: This study aims to develop a permit administration management information system at Sumbawa technology university in order to facilitate data management activities and submission of permits for all lecturers and staff of the Sumbawa technology university.The study used a qualitative descriptive method to describe the situation in the study site in detail and allow it to develop during the research process. This software design method uses the waterfall methodMethods of data collection using observation, literature and document research. The results of this study are a system that has been developed so that it can help make it easier for employees to carry out day-to-day permits and leave and make it easier for staffing to carry out permit and leave data management.

Keywords : Web, Permit, Leave, System, Information

\section{PENDAHULUAN}

Teknologi adalah salah satu apek penting dalam kehidupan yang tak kenal selesai dalam berkembanga menjadi lebih baik, hal tersebut tidak hanya untuk memperbaiki kekurangan pada tenologi sebelumnya namun menciptakan sesuatu yang baru. Salah satu jenis teknologi yang sering digunakan adalah teknologi informasi. Penggunaan teknologi informasi sangatlah berperan penting terutama dalam dunia kerja untuk membantu pekerjaan agar lebih mudah dan efisien dalam menyelesaikan masalah.

Universitas Teknologi Sumbawa adalah salah satu perguruan tinggi swasta yang telah menerapkan sistem informasi pada beberapa aspek kegiatannya, salah satunya adalah sistem informasi manajemen administrasi izin. Namun pada sistem ini masih terdapat kekurangan yang sangat mendasar, yaitu jenis izin yang masih belum sesuai dengan kebutuhan dan cuti yang termasuk izin masih dilakukan diluar sistem atau masih dilakukan secara manual yaitu menggunakan formulir yang dicetak secara mandiri oleh pegawai bersangkutan, izin tidak dapat menyesuaikan dengan kebutuhan, tidak ada pemberitahuan terkait izin ke atasan pemohon ataupun pemohon tersebut, tidak ada validasi data inputan, keamanan data.

Penelitian ini dilakukan untuk mengembangkan sistem yang sedang berjalan agar sesuai kebutuhan dan mempermudah seluruh pegawai Universitas Teknologi Sumbawa dalam mengajukan izin/cuti dan mempermudah kepegawaian dalam mengelola data izin/cuti.

\section{TINJAUAN PUSTAKA}

Dalam penelitian ini, peneliti menggunakan hasil penelitian yang telah dilakukan peneliti lain untuk dijadikan acuan.

${ }^{[1]}$ Anggi Dwi Lestari (2016) dengan "Sistem Informasi Cuti Karyawan berbasis web pada PT.Bank Negara Indonesia (Persero) Tbk kantor cabang utama harmoni jakarta". Anggi mengatakan proses pengajuan cuti masih dilakukan secara manual meskipun terdapat fasilitas pendukung yaitu PC namun masih memungkinkan terjadinya kesalahan atau ketidaktepatan data cuti karyawan Bank BNI. Dari penelitian tersebut menghasilkan web sistem informasi untuk memperbaiki permasalahan cuti agar lefik efektif dan efisien.

Dan berikut beberapa landasan teori yang digunakan penelitian ini :

1. Sistem Informasi

${ }^{[2]}$ Definisi sistem menurut Mulyadi (2016),

Sistem adalah "suatu jaringan prosedur yang dibuat menurut pola yang etrpadu untuk melaksanakan kegiatan pokok perusahaan". 


\section{Izin}

${ }^{[3]}$ Menurut Sutedi Adrian (2011), Izin adalah suatu persetujuan dari penguasa berdasarkan Undang-Undang atau peraturan pemerintah untuk dalam keadaan tertentu menyimpang dari ketentuan-ketentuan larangan peraturan perundang-undangan.

\section{Pegawai}

${ }^{[4]}$ Menurut Robbins (2006), pegawai adalah “ orang pribadi yang bekerja pada pemberi kerja baik sebagai pegawai tetap atau tidak, berdasarkan kesepakatan kerja baik tertulis maupun tidak tertulis, untuk melaksanakan suatu pekerjaan dalam jabatan atau kegiatann tertentu yang diterapkan oleh pemberi kerja.

\section{UML (Unified Modelling Language)}

${ }^{[5]}$ Menurut Utami (2015), UML adalah salah satu standar Bahasa yang banyak digunakan di dunia industri untuk mendefinisikan requirement, membuat analisis dan desain, serta menggambarkan arsitektur dalam pemrograman berorientasi objek.

\section{Waterfall}

${ }^{[6]}$ Menurut Pressman (2015), model waterfall adalah model klasik yang bersifat sistematis, berurutan dalam membangun software.

Model ini dikenalkan oleh Winston Royce pada tahuan 1970 dan masih tetap digunakan sampai sekarang karena model ini menggunakan pendekatan secara sistematis dan berurutan.

Berikut adalah tahapan-tahapan menurut pressman :

\section{a. Communication (Project Initiation \&} Requirements Gathering).

Sebelum seeorang Software Engineering (SE) sangat diperlukan untuk berkomunikasi dengan palanggan untuk mengetahui dan memahami permasalahan yang ingin diselesaikan dengan menggunakan sistem yang akan dibangun nantinya, sehingga dengan mengetahui permasalahan dan keinginan pelanggan memudahkan dalam menganalisis permasalahan dan mengumpulkan data-data yang dibutuhkan serta menentukan fungsi dan fitur dari sistem tersebut.

b. Planning (Estimating, Scheduling, Tracking)

Setelah melakukan persiapan awal maka pada tahap ini adalah menjelaskan, membaca keadaan termasuk kebutuhan, estimasi waktu yang dibutuhkan sekaligus menjadwalkan apa saja yang akan dikerjakan. Selain itu melacak proses pengerjaan sistem.

\section{c. Modeling (Analysis \& Design)}

Pada tahapan ini adalah tahap untuk merancang dan memodelkan sistem seperti perancangan struktur data, membuat Diagram konteks, Data Flow Diagram, dan lain-lain, mendesain tampilan interface dan algoritma program.

\section{d. Construction (Code \& Test)}

Setelah merancang maka pada tahap ini merupakan tahap menerjemahkan desain ke dalam code atau bahasa pemrograman yang dapat dimengerti oleh mesin. Setelah penulisan code langkah selanjutnya adalah menguji coba code dan sistem yang telah dibuat untuk mengetahui kesalahan agar dapat diperbaiki sebelum diimplemetasikan.

e. Deployment (Delivery, Support, Feedback).

Tahapan ini adalah tahap mengimplementasikan software, memlihara software secara berkala, memperbaikan jika ada bug, mengevaluasi software dan melakukan pengembangan berdasarkan feedback yang dari pengguna.

\section{METODE}

Dalam mengembangkan sistem ini, peneliti menggunakan metode penelitian deskriptif kualitatif. Untuk menunjang penelitian berikut ini metode yang digunakan, yaitu :

a. Studi dokumen

Penggumpulan informasi melalui catatan arsip dan dokumen lainnya yang berhubungan dengan studi kasus ini.

b. Observasi

Meotde ini dilakukan dengan melakukan pengamatan secara langsung pada sistem maupun tempat penelitian.

c. Studi pustaka

Studi pustaka dilakukan dengan mengumpulkan informasi terkait dengan topik yang sedang diteliti seperti buku-buku, karya ilmiah, dan sumber lainnya

Dalam mengembangkan sistem, peneliti menggunakan waterfall karena membuat pengerjaan sistem lebih efektif dan efisien karena memiliki tahapan. Selain hal tersebut karena kebutuhan yang diperlukan dalam sistem sudah jelas.

\section{HASIL DAN PEMBAHASAN}

A. Analisis sistem berjalan

Setelah melakukan analisa dan diskusi singkat dengan bagian kepegawaian dan Unit Pelakasana Teknis Information Technology berikut kesimpulannya :

a. Menambahkan fitur pengajuan cuti dengan hak cuti.

b. Menyesuaikan jenis izin dengan kebutuhan.

c. Menambahkan email notifikasi.

d. Menambahkan fitur Export dan Import data. 
e. Menambahkan fitur backup melalui sistem.

f. User interface tidak user friendly dan responsive.

B. Perancangan sistem

1. Use Case Diagram

Sistem ini memiliki beberapa actor yaitu, pegawai, manajer/dekan/wakil rector, rector, kepegawawaian/admin dan administrator. Untuk mengetahui peran masing-masing aktor dapat dilihat pada gambar dibawah ini :

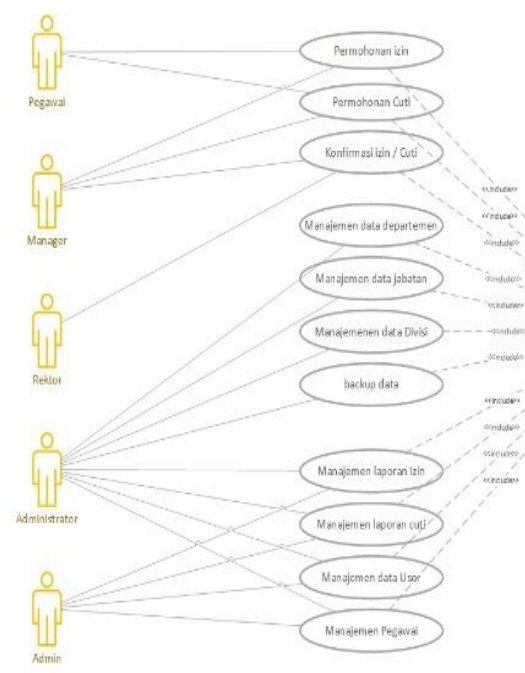

Gambar 1. Use Case Diagram

2. Activity Diagram

a. Activity pengajuan izin pegawai

Untuk melakukan izin, pegawai bersangkutan diharuskan login terlebih dahulu. Setelah login, pegawai mengisi form dan setelah selesai sistem akan mengirim email pemberitahuan ke atasan pegawai bersangkutan.

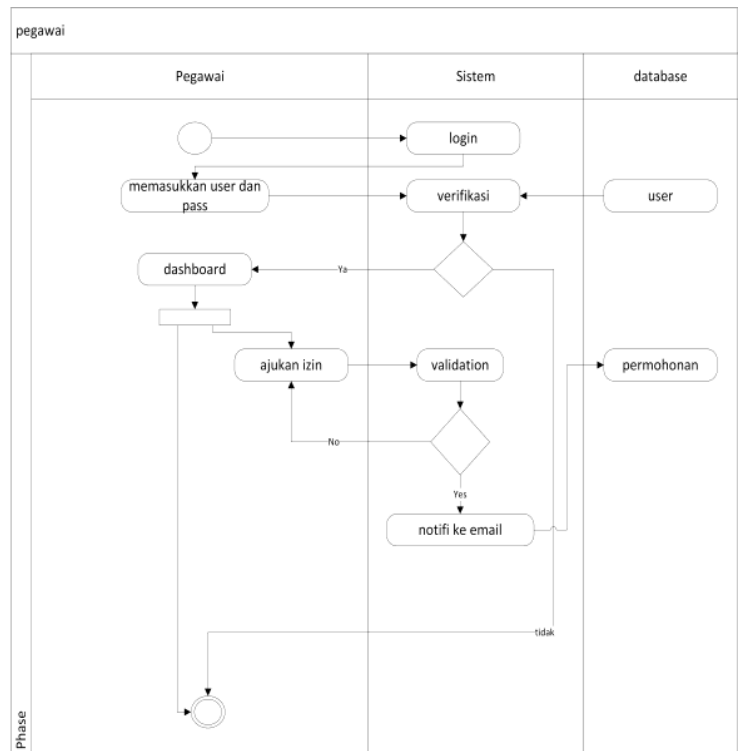

Gambar 2. Activity pengajuan izin pegawai b. Activity pengajuan cuti pegawai

Alur pengajuan cuti memiliki alur yang sama dengan izin. Namun pada cuti, permohonan akan disimpan jika sisa cuti yang diisi sesuai dengan sisa yang dapat diambil.

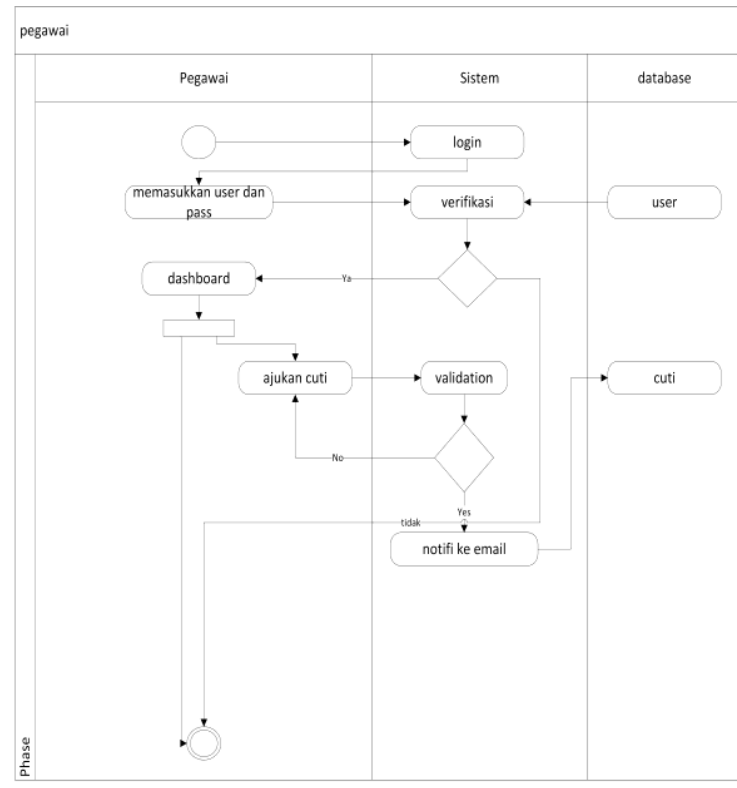

Gambar 3. Activity pengajuan cuti pegawai

c. Activity konfirmasi izin

Setiap mengkonfirmasi izin, sistem akan mengirimkan email pemberitahuan ke pegawai bersangkutan terkait hasil konfirmasi.

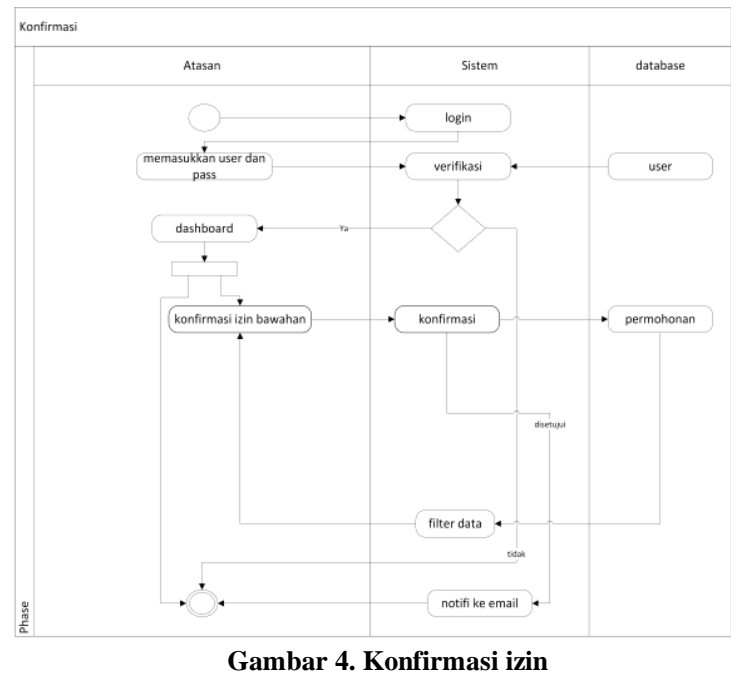

d. Activity konfirmasi cuti

Pada sistem ini, atasan hanya perlu mengkonfirmasi, karena sistem telah melakukan pengecekan secara otomatis terhadap sisa cuti yang dapat diambil oleh seorang pegawai sebelum tersimpan. 
JINTEKS (Jurnal Informatika Teknologi dan Sains) ISSN 2686-3359 (Online)

Vol. x No. 2, Bulan Tahun, hlm. xx - xx

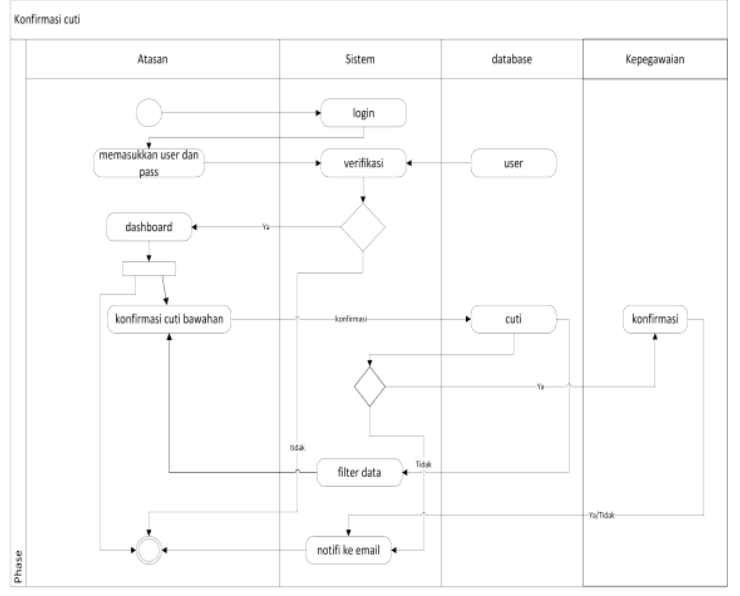

Gambar 5. Activity konfirmasi cuti

e. Activity kepegawaian

Berikut adalah activity yang dapat menjelaskan peran yang dilakukan oleh admin atau psdm.

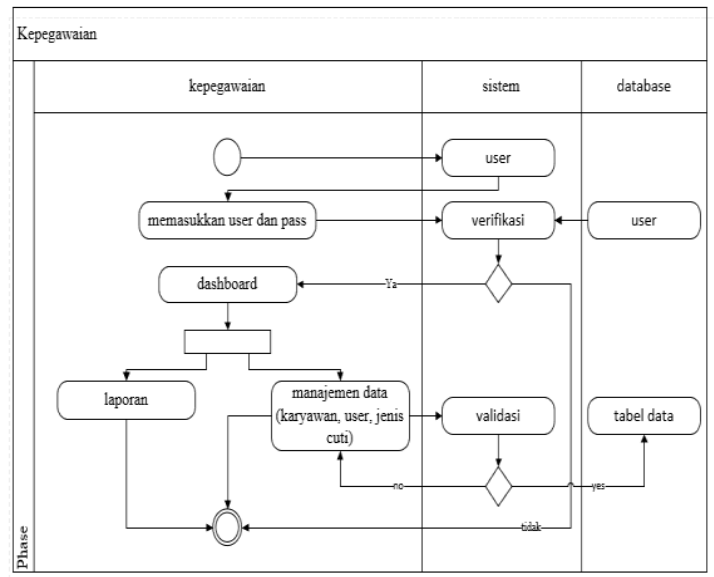

Gambar 6. kepegawaian

f. Activity administrator

Administrator memiliki akses penuh ke dalam sistem dan apa saja yang dapat diakses oleh admin atau psdm.

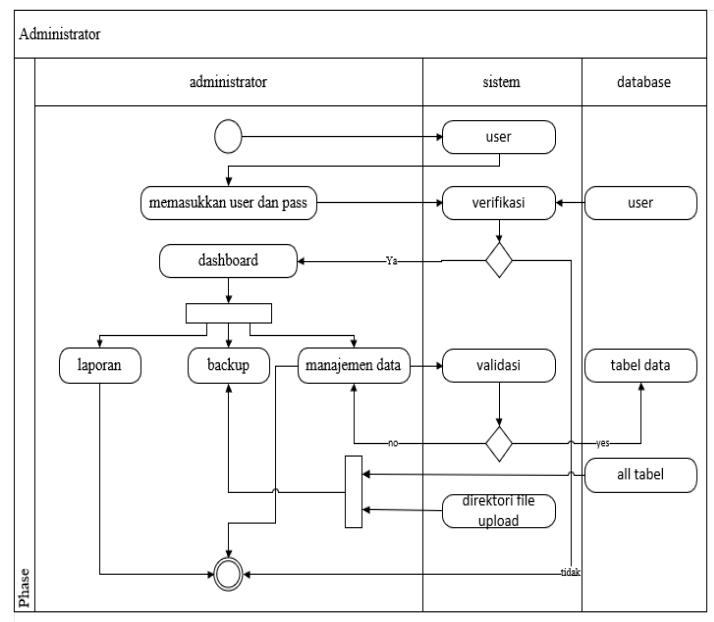

Gambar 7. Activity administrator

\section{Class Diagram}

Adapaun class diagram dari perancangan Sistem Informasi Manajemen Administrasi Izin di Universitas Teknologi Sumbawa terdapat 11 class yang saling berhubungan.

Dimana penjelasan hubungan antar class sebagai berikut :

a. Satu jabatan bisa dimiliki oleh satu atau lebih karyawan.

b. Satu departemen bisa berisi satu atau lebih karyawan.

c. Satu bagian departemen bisa berisi satu atau lebih karyawan.

d. Satu atau lebih departemen hanya boleh memiliki satu bagian departemen.

e. Satu dashboard bisa diakses oleh satu atau lebih karyawan.

f. Satu karyawan hanya boleh memiliki satu akses.

g. Satu atau lebih permohonan cuti bisa dilakukan oleh satu karyawan.

h. Satu atau lebih permohonan izin bisa dilakukan oleh satu karyawan.

i. Satu karyawan hanya boleh memiliki satu user.

j. Satu karyawan boleh memiliki satu atau lebih sisa cuti.

Berikut gambar dari Class diagram berdasarkan penjelasan diatas.

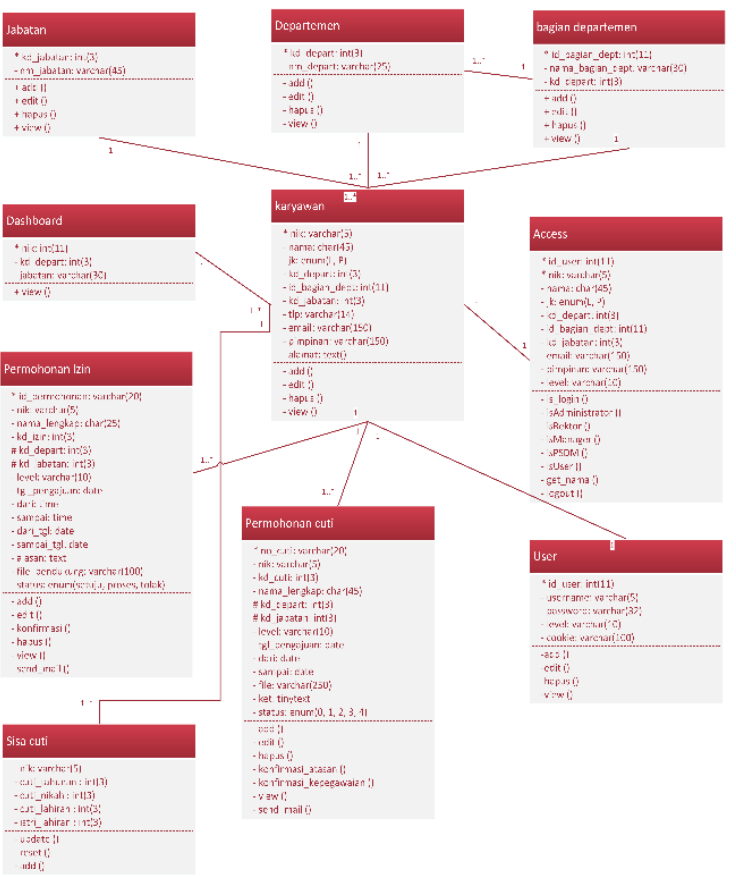

Gambar 8. Class diagram

4. Entity Relationship Diagram (ERD)

Untuk menggambarkan relasi antar entitas yang terdapat pada sistem ini, dapat dilihat pada gambar dibawah ini : 


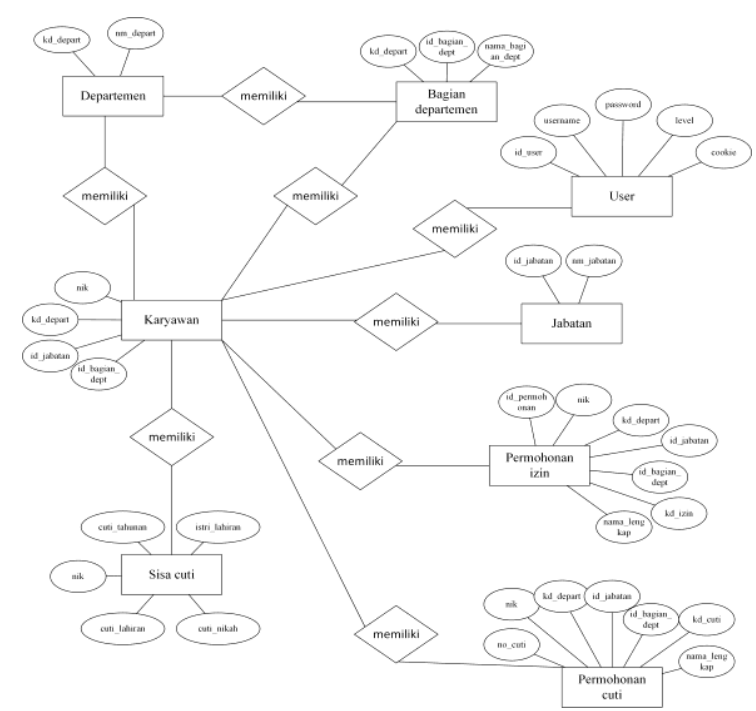

Gambar 9. Entity Relationship Diagram (ERD)

Gambar diatas menunjukkan terdapat 9 entitas yang saling berhubungan yaitu departemen, bagian departemen, jabatan, user, karyawan, sisa cuti, permohonan izin, permohonan cuti dan jenis cuti.

C. Implementasi

1. Cuti

Untuk melakukan cuti, pegawai melakukan inputan melalui form dibawah ini, dengan jenis izin yang diisi secara otomatis oleh sistem sesuai jenis cuti cuti yang dipilih pada menu cuti.

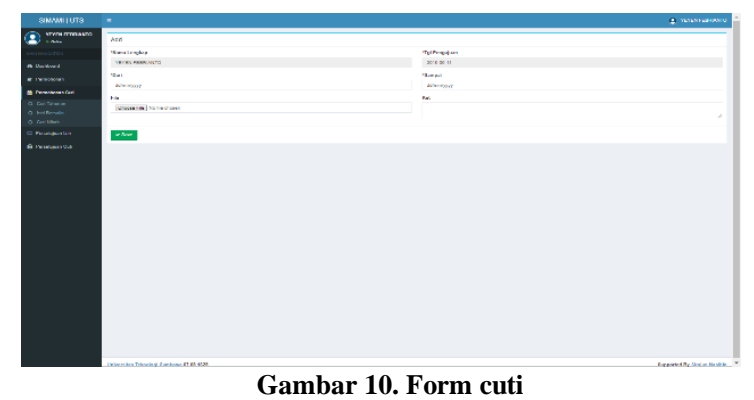

2. Izin

Form ini akan lebih mempermudah pegawai sehingga tidak lagi dibingungkan dengan inputan yang membingungkan. Keterangan waktu izin akan ditampilkan sesuai dengan jenis izin yang dipilih pada form.

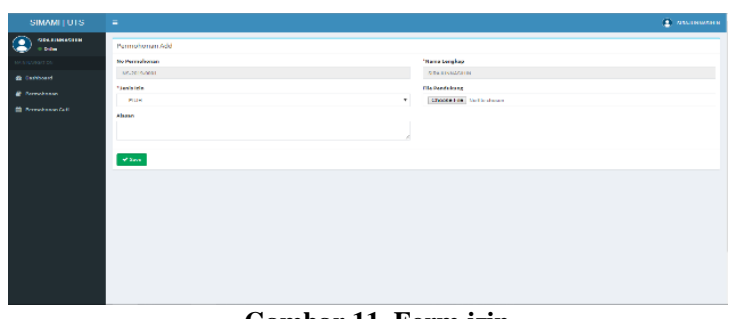

Gambar 11. Form izin

\section{Import karyawan}

Untuk mempermudah kepegawaian atau administrator dalam mengelola data karyawan, administrator atau kepegawaian dapat memnggunakan salah satu fitur dibawah ini :

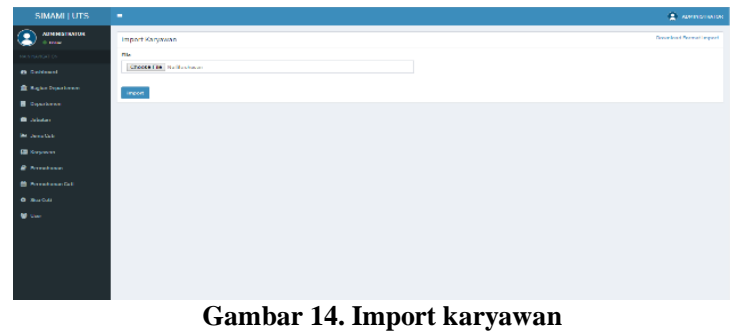

Gambar 14. Import karyawan

\section{Konfirmasi cuti}

Permohonan yang telah divalidasi oleh sistem akan ditampilkan pada daftar yang membutuhkan konfirmasi atasan masingmasing sesuai dengan departemen.

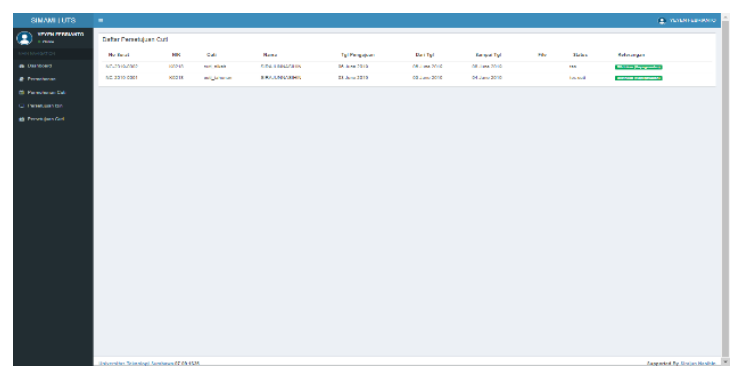

Gambar 15. Konfirmasi cuti atasan

Permohonan yang dikonfirmasi setuju oleh atasan akan diteruskan ke bagian psdm atau kepegawaian untuk menindak lanjuti. Namun berbeda dengan proses manual sebelmunya, psdm tidak lagi melakukan secara manual pengecekan terhadap sisa cuti yang dapat diambil karena telah dilakukan oleh sistem secara otomatis pada saat pegawai mengisi form.

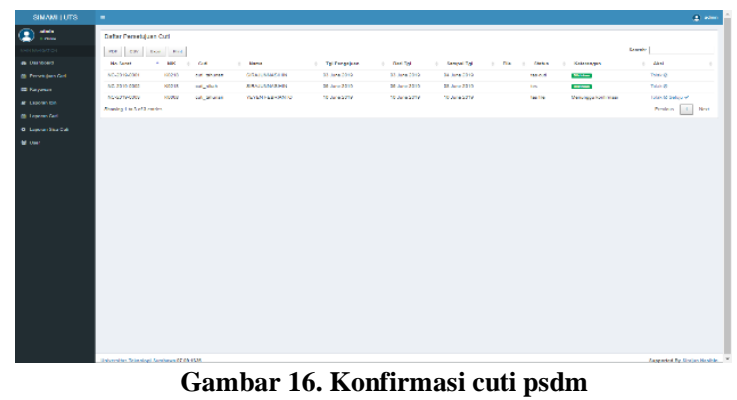

5. Sisa cuti

Dengan interface dibawah ini, pegawai dapat melakukan monitoring secara manual dan membuat laporan sisa cuti pegawai. Selain hal tersebut, sisa cuti yang dimiliki oleh pegawai dapat di reset sewaktu sesuai kebijakan kepegawaian/psdm. 


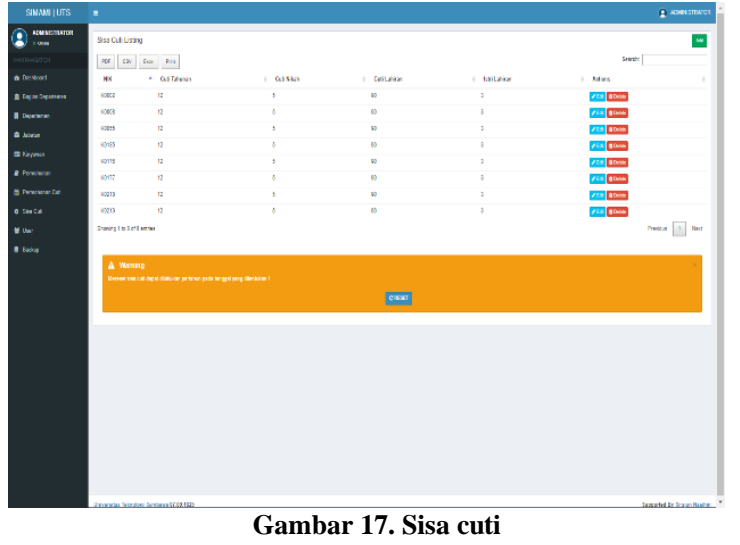

6. Report

Untuk mempermudah dalam memetakkan data, laporan dapat dibuat berdasarkan per departemen dan range tanggal yang ingin dijadikan sebagai pelaporan. Selain per departemen,terdapat jugapilihan untuk pelaporan yang mencakup semua departemen.

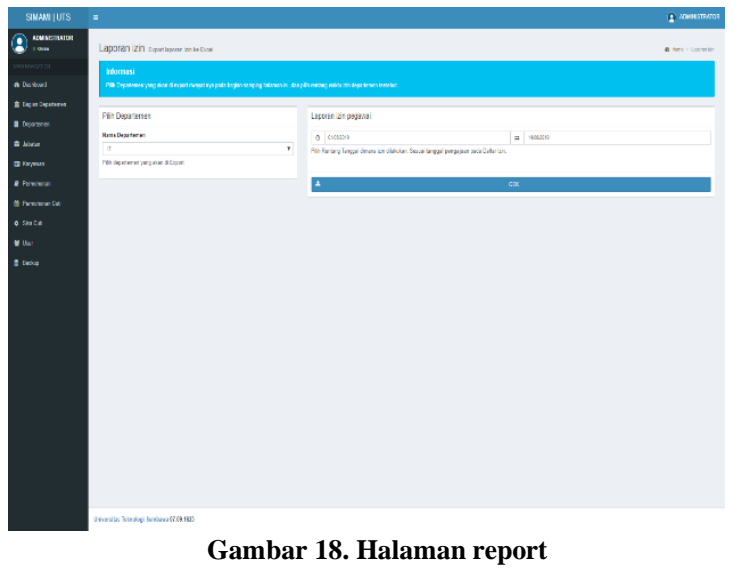

Setelah memilih mencetak laporan per departemen atau semua departemen, administrator atau psdm harus memilih range tanggal dan melakukan pengecekan ketersediaan data. Data akan ditampilkan seperti pada gambar dibawah ini jika tidak kosong.

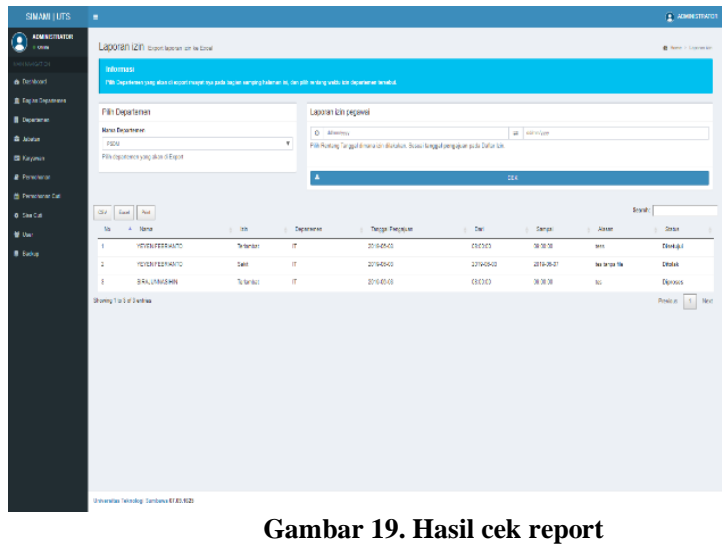

\section{KESIMPULAN DAN SARAN}

Berdasarkan hasil penelitian yang dilakukan dan kuisioner yang diisi oleh psdm, penulis dapat menyimpulkan beberapa hal yaitu :

a. Berhasil mengembangkan sistem informasi manajemen administrsi izin di Universitas Teknologi Sumbawa.

b. Mempermudah dan membantu pihak kepegawaian dalam mengelola data izin dan cuti seluruh pegawai Universitas Teknologi Sumbawa.

Dalam sebuah penelitian ataupun penulisan skripsi tentunya tidak akan terlepas dari kekurangan yang dapat terjadi sehingga harapannya agar peneliti selanjutnya dapat menutupi kekurangan pada penelitian ini, seperti :

a. Sistem tidak dapat mengenal tanggal merah sehingga sistem tetap menghitungnya seperti hari biasa.

b. Tidak terintegrasi sempurna dengan sistem yang lain.

c. User Interface kurang menarik.

Selain itu, pengembangan juga diperlukan mengikuti perkembangan teknologi yang tidak kenal henti juga menyebabkan perlunya pengembangan mengikuti perkembangan teknologi untuk menutupi kekurangan pada teknologi yang digunakan sebelumnya

\section{DAFTAR PUSTAKA}

[1] Lestari, Anggi Dwi, 2016, Sistem Informasi cuti karyawan berbasis web pada PT BNI Tbk kantor cabang utama harmoni Jakarta.

[2] Mulyadi, 2016, Sistem Akuntansi, Salemba Empat, Jakarta Selatan.

[3] Sutedi, Adrian, 2012, Hukum Perizinan dalam Sektor Pelayanan Publik, Simar Grafika, Jakarta.

[4] P.Robbins, Stephen, 2006, Perilaku Organisasi, Edisi Kesepuluh, Indeks, Jakarta.

[5] Utami, L.A, 2014, Sistem Informasi Administrasi Pasien pada Klinik Keluarga Depok, Konferensi Nasional Ilmu Pengetahuan dan Teknologi, Jakarta.

[6] Pressman, R.S, 2015, Rekayasa Perangkat Lunak Pendekatan Praktisi Buku 1, AndiPublisher, Yogyakarta. 